\title{
PESSOAS ACIMA DE 50 ANOS COM AIDS: IMPLICAÇÕES PARA 0 DIA-A-DIA
}

\author{
People with more than 50 years old with aids: implications to everyday life \\ Personas con más de 50 años que tienen sida: implicaciones para el cotidiano
}

Soraia Romera Machiesqui ${ }^{1}$

Aline Cammarano Ribeiro ${ }^{4}$
Stela Maris de Mello Padoin ${ }^{2}$

Tassiane Ferreira Langendorf ${ }^{5}$

\section{RESUMO}

Este estudo caracteriza-se por ser uma pesquisa qualitativa que objetivou descrever as implicações relacionadas ao dia-a-dia de pessoas acima de 50 anos que têm a síndrome da imunodeficiência adquirida. A pesquisa foi realizada num hospital de ensino na região sul do Brasil. A produção dos dados foi desenvolvida com a dinâmica de criatividade e sensibilidade Mapa Falante, por um grupo de cinco participantes. Para a análise, foi aplicada a técnica de análise temática do conteúdo. Das produções artísticas e depoimentos, emergiram os efeitos decorrentes da descoberta do diagnóstico; da compreensão de que tem uma vida normal apesar da doença; da fé em Deus; do preconceito e discriminação e do silêncio da condição sorológica. Conclui-se que as ações de cuidado devem contemplar as dimensões biológicas, clínica, social e subjetiva de modo corresponsável vislumbrando a autonomia para o cuidado com a sua saúde e para as escolhas de sua vida.

Palavras-chave: Síndrome da Imunodeficiência Adquirida. Enfermagem. Saúde do Idoso

\begin{abstract}
It is a qualitative research that aimed to describe the implications related to everyday life of people with more than 50 years old who acquired immunodeficiency syndrome. It was carried out at a training hospital in the southern Brazil. The data were generated by a dynamic technique using the creativity and sensibility dynamic Speaker Map, with five participants in the group. The data were submitted to a content thematic analysis. From artistic productions and reports, emerged the effects from diagnosis discovered; the comprehension that they have a normal life in spite of disease; the faith in God; the prejudice and discrimination; and the silence about the serologic condition. We concluded that the care actions must consider the biological, clinical, social and subjective dimensions in a co-responsibility way in the perspective to their autonomy to health care and to choices of their life.
\end{abstract}

Keywords: Acquired immunodeficiency syndrome. Nursing. Health of the elderly

\section{Resumen}

Investigación cualitativa que tuvo por objetivo describir las implicaciones relacionadas al cotidiano de personas con más de 50 años de edad que tienen el síndrome de inmunodeficiencia adquirida. Realizada en hospital de enseñanza en la región sur de Brasil. La producción de los datos fue desarrollada con dinámica de creatividad y sensibilidad mapa hablante, por un grupo de cinco participantes. Para el análisis, fue aplicada la técnica de análisis temático del contenido. De las producciones artísticas y declaraciones emergieron los efectos decurrentes de la descubierta del diagnóstico; de la comprensión de que tiene una vida normal a pesar de la enfermedad; de la fe en Dios; del prejuicio y discriminación y del silencio de la condición serológica. Se concluye que las acciones de cuidado deben contemplar las dimensiones biológicas, clínica, social y subjetiva de modo co-responsable vislumbrando la autonomía para el cuidado con su salud y para las elecciones de su vida.

Palabras clave: Síndrome de inmunodeficiencia adquirida. Enfermería. Salud del anciano.

${ }^{1}$ Enfermeira. Membro do Grupo de Pesquisa Cuidado à Saúde das Pessoas, Famílias e Sociedade. Santa Maria - RS. Brasil. E-mail: soraiarm@hotmail.com, ${ }^{2}$ Enfermeira Doutora. Professora Adjunta do Departamento de Enfermagem do Centro de Ciências da Saúde da Universidade Federal de Santa Maria. Membro do Grupo de Pesquisa Cuidado à Saúde das Pessoas, Famílias e Sociedade. Santa Maria - RS. Brasil. E-mail: stelamaris_padoin@hotmail.com, ${ }^{3}$ Enfermeira Doutora. Professora Adjunta do Departamento de Enfermagem do Centro de Ciências da Saúde da Universidade Federal de Santa Maria. Membro do Grupo de Pesquisa Cuidado à Saúde das Pessoas, Famílias e Sociedade. Santa Maria - RS. Brasil. Email: cris_depaula1@hotmail.com, ${ }^{4}$ Enfermeira. Mestranda do Curso de Pós-Graduação em Enfermagem da Universidade Federal de Santa Maria. Membro do Grupo de Pesquisa Cuidado à Saúde das Pessoas, Famílias e Sociedade. Santa Maria - RS. Brasil. E-mail: lilicammarano@yahoo.com.br , ${ }^{5}$ Acadêmica do $7^{\circ}$ semestre do Curso de Graduação em Enfermagem da Universidade Federal de Santa Maria. Membro do Grupo de Pesquisa Cuidado à Saúde das Pessoas, Famílias e Sociedade. Bolsista de iniciação científica FAPERGS. Santa Maria - RS. Brasil. E-mail: tassi.lang@gmail.com 


\section{INTRODUÇÃO}

A epidemia da síndrome da imunodeficiência adquirida (AIDS) surgiu no mundo há três décadas e, desde então, acomete em torno de 544.846 pessoas no Brasil, segundo casos notificados entre 1980 e 2009. As regiões mais afetadas são a Sudeste (59,3\% dos casos) e a Sul $(19,2 \%) .{ }^{1}$

A prevalência dos casos de AIDS concentra-se na faixa etária entre 25 e 49 anos. Entretanto, destaca-se que há um aumento no quantitativo de casos notificados de pessoas acima de 50 anos, que corresponde a segunda maior incidência de AIDS, por idade, no país. ${ }^{2}$ Entre as 53.189 notificações nessa população, tem-se 34.864 do sexo masculino e 18.325 do sexo feminino. ${ }^{1}$ No Estado do Rio Grande do Sul (RS), de 1980 a 2008, totalizaram-se 4.695 casos notificados de pessoas acima de 50 anos. ${ }^{3}$

As notificações evidenciam a vulnerabilidade desse segmento populacional às infecç̃oes sexualmente transmissíveis (IST), dentre elas, a infecção pelo HIV. ${ }^{4}$ Nesse período, o avanço da ciência farmacêutica e médica proporcionou não só 0 prolongamento da vida sexual ativa das pessoas acima de 50 anos, mas também a condição de cronicidade da doença, especialmente devido à evolução terapêutica.

Após o início da terapia antirretroviral houve uma redução na mortalidade entre as pessoas que têm AIDS e um aumento da sua perspectiva de vida, o que remete às implicações relacionadas ao dia-a-dia. Essas se caracterizam por enfrentamentos, os quais perpassam a descoberta do diagnóstico, acompanhamento terapêutico, a discriminação e o preconceito da doença. ${ }^{5}$ Tais questões se somam ao processo de envelhecer com suas especificidades nas dimensões biológicas, sociais, psicológicas enfatizando a complexidade do tema.

Estudos científicos apontam que as vivências com o diagnóstico IST, principalmente a AIDS, possibilitam o surgimento de quadros depressivos nos portadores, pois há a crença de que a doença promove o afastamento do convívio social e o sofrimento de preconceito. Demonstram ainda que 0 período de enfrentamento do diagnóstico gera consequências significativas à vida do portador, gerando sentimentos como a impotência e dificuldade em enfrentar essa fase da vida. . $^{6.7}$

Essas questões se caracterizam de forma intensa na vida das pessoas que possuem AIDS, pois envolvem um processo de adaptação ao seu dia-a-dia, para que possam viver de maneira saudável. Sendo assim, esse estudo teve como objetivo descrever as implicações relacionadas ao dia-a-dia de pessoas acima de 50 anos que têm AIDS.

\section{MÉTODO}

Trata-se de uma pesquisa qualitativa com protocolo aprovado pelo Comitê de Ética em Pesquisa da Universidade Federal de Santa Maria - UFSM, sob CAAE nº 0090.0.243.00007. Este estudo foi desenvolvido no serviço de infectologia do
Hospital Universitário de Santa Maria (HUSM), localizado na região centro-oeste do Estado do Rio Grande do Sul/RS.

Os sujeitos do estudo atenderam aos critérios de inclusão: idade igual ou superior a 50 anos e que estão em tratamento antirretroviral (TARV), cadastrados na Unidade Dispensadora de Medicamentos (UDM) do HUSM e residentes no município de Santa Maria. Totalizaram um grupo de cinco pessoas.

Para produção dos dados, foram utilizadas as Dinâmicas de Criatividade e Sensibilidade (DCS), fundamentadas no Método Criativo e Sensível (MCS). Esse Método é subsidiado pela pedagogia crítica-reflexiva de Freire. A utilização das DCS ocorreu a partir de 1997, com a tese de doutoramento da professora e enfermeira Ivone Evangelista Cabral. Essa constitui uma alternativa à pesquisa em enfermagem, considerando um objeto de estudo que possui particularidades com maiores possibilidades de entendimento se investigadas e discutidas em grupo. A DCS propõe um espaço de discussão coletiva, em que a experiência vivenciada é abordada por meio de uma produção artística. $^{8}$

Nesta pesquisa, foi desenvolvida a dinâmica do Mapa Falante, que se caracteriza como produção artística, visto que consiste na construção de um mapa desenhado pelos participantes com o intuito de descrever as implicações relacionadas ao dia-a-dia de pessoas acima de 50 anos que têm AIDS. Essa dinâmica foi utilizada pela primeira vez como DCS em um estudo sobre a rota do álcool na vida de adolescentes de uma comunidade do município do Rio de Janeiro. ${ }^{9}$

Os materiais utilizados foram crachás de identificação dos participantes, cadeiras dispostas ao redor de uma mesa, gravador de fita k7, folhas de cartolina, canetas e lápis coloridos e folhas de papel A4. A questão norteadora do debate foi: A partir da casa de vocês, quais são os lugares por onde vocês passam para dar seguimento ao tratamento antirretroviral?

Para análise dos dados, foi utilizada a técnica de Análise Temática do Conteúdo que consiste em descobrir núcleos de sentido, cuja presença ou frequência sejam expressivas para o objetivo analítico visado. Constituiu-se de três etapas: ordenação, classificação dos dados e análise final. ${ }^{10}$

A etapa de ordenaçã̃o consistiu na transcrição dos dados gravados e leitura exaustiva do corpus da pesquisa, a fim de determinar as unidades de registro: frases ou palavras-chave que aparecem com certa frequência nos depoimentos, caracterizadas como ideias centrais ou aspectos relevantes, seguida da determinação das unidades de contexto: delimitação do contexto de compreensão da unidade de registro. ${ }^{10}$

A partir dessa determinação, deu-se a leitura exaustiva do corpus da pesquisa, a exploração do material por meio dos recortes de fragmentos do texto de unidades de registro. $\mathrm{A}$ etapa de classificação possibilitou construir as categorias empíricas responsáveis pela especificação dos temas e os conceitos teóricos que orientaram a descoberta e a construção dos núcleos de sentido, que dão o embasamento da análise. 
Para tanto, foi desenvolvido um quadro analítico. Emergiram as categorias: 0 cotidiano terapêutico e as implicações da AIDS no dia-a-dia.

A etapa de análise final baseou-se no tratamento dos resultados obtidos e interpretação, procurando articular o material estruturado com as ideias dos depoimentos e 0 referencial teórico, visando à identificação do conteúdo subjacente ao que é manifestado.

\section{RESULTADOS E DISCUSSÃO}

Participaram da dinâmica grupal para produção de dados da pesquisa cinco pessoas com idade igual ou maior que 50 anos, dentre os quais: uma mulher de 69 anos e diagnóstico de AIDS há 2 anos; um homem de 60 anos e diagnóstico há 8 anos; um homem de 55 anos e diagnóstico há 6 anos; dois homens de 50 anos, um com diagnóstico há 21 e 0 outro há 8 anos.

Apresentaremos um recorte dos dados qualitativos, mais especificamente a categoria: implicações da AIDS no diaa-dia de pessoas acima de 50 anos. Essa categoria foi composta por subcategorias: efeitos decorrentes da descoberta do diagnóstico; da compreensão de que tem uma vida normal apesar da doença; a fé em Deus como modo de enfrentamento; vivências e experiências como o preconceito e a discriminação; e o silêncio da condição sorológica.

Durante a dinâmica, os depoimentos revelaram questões relacionadas à descoberta da infecção, a qual foi para a maioria impactante, pois é uma situação inesperada, trazendo sentimentos de tristeza e desespero.

[...] eu tinha vontade de me matar, eu tinha vontade de procurar um rio, me enfiar de cabeça, foi uma coisa muito triste sabe? Uma coisa que eu não esperava [...] (M1).

\section{[...] quando eu descobri, entreiem parafuso, em pânico [...] e aí eu tava entrando em depressão [...] (H2).}

Esses mesmos sentimentos são relatados em estudo realizado com mulheres, as quais, quando se descobriram portadoras do vírus da imunodeficiência humana (HIV), mostramse desesperadas e não aceitaram o diagnóstico, referindo sua lealdade ao companheiro, relataram que isso foi uma decepção, pensaram na possibilidade de se matar devido ao pânico da doença, ${ }^{11}$ situação semelhante ao que foi relato por M1 neste estudo.

[...] antes, no começo, eu culpava ele (companheiro), dizia que era ele que tinha me transmitido [...] nessa cirurgia que eu fiz [...] precisei de transfusão de sangue, foi aí que eu descobri que foi onde eu fui contaminada [...] eu entrei num desespero [...] (M1).
No depoimento de M1, referente à forma de aquisição do HIV, observa-se que ela acredita ter se infectado por transfusão sanguínea ou durante uma cirurgia. Em contraponto, estudos trazem que, atualmente, a AIDS dissemina-se entre a população em geral, sendo a principal forma de exposição ao HIV as relações heterossexuais, ao contrário do início da epidemia em que havia predominância de contágio entre grupos de riscos. ${ }^{2,12}$

Em estudos realizados com pessoas que têm AIDS, na faixa etária acima de 50 anos, observou-se a predominância da forma de transmissão do vírus por relação sexual, seguida do uso de drogas injetáveis. Tais achados são convergentes com o boletim epidemiológico. ${ }^{1,2,13-14}$

É possível observar a fragilidade dos pacientes ao receberem um diagnóstico inesperado, principalmente por não se perceberem como seres vulneráveis ao HIV. Esses sentimentos podem estar relacionados à surpresa e à incerteza sobre a forma de exposição ao vírus. Neste estudo, somente um participante afirmou que adquiriu o HIV por relação sexual, os outros não sabem ao certo.

[...] sei lá como aconteceu, não sei, eu trabalhava na época, eu era motorista [...] sei lá, eu nem sei como explicar, eu nunca andei com outra pessoa, com outra mulher. Não sei, isso aí é coisa que eu nem posso explicar que vão duvidar de mim, né? [...] (H1)

[...] viajei muito por esse Brasil, atendi muito acidente, botei muito a mão no sangue, não sei se isso contagia ou não, não sei se foi por contato com sangue, por sexo, nunca usei droga, já doei sangue em épocas passadas, então acredito que tenha sido sexual $[\ldots](\mathrm{H} 2)$

Não são raras as pessoas acima de 50 anos que acreditam na improbabilidade de adquirirem DST. Essa concepção poderá ser associada a uma prerrogativa de que 0 sexo acontece na juventude, a qual poderá contribuir para manter esse grupo fora das ações preventivas da epidemia. ${ }^{2}$ Tanto essa população como os profissionais de saúde têm dificuldades para falar e compreender a sexualidade nessa fase da vida. A invisibilidade da sexualidade implica uma assistência fragmentada, pois muitas ações como prevenção de DST não são realizadas de maneira efetiva.

Em pesquisa realizada com médicos, tem-se que, muitas vezes, esse profissional considera as pessoas com idade avançada como assexuadas, dificilmente os indagam sobre sua vida sexual ou discutem sobre prevenção da AIDS $^{2}$. Esta atitude poderá implicar não só no diagnóstico tardio, como também no aumento da exposição ao vírus.

No decorrer da dinâmica, foi possível observar, entre os participantes, diferentes maneiras de enfrentar o diagnóstico 
da AIDS. Para alguns, o diagnóstico se torna uma espécie de ameaça à solidão, e, não sabendo lidar com o fato de envelhecer com AIDS, os pacientes tendem a se isolar, ${ }^{14,5}$ como pode-se visualizar na produção artística somada ao seu depoimento.

\section{[...] as horas que eu estou aborrecida eu vou pra lá} (na horta) [...] Sei lá, as vezes a gente se acha sozinha né? [...] Tem as coisas, mas às vezes parece que não tem nada [...] é que eu nunca fui uma pessoa sozinha, sabe? Aí agora depois que me aconteceu isso é que eu fiquei assim [...] eu gosto é de estar num canto quieta! Tenho me sentindo melhor sozinha, mas as vez bate uma solidão, que é muito ruim [...] (M1).

Entretanto, em resultados de outro estudo, o diagnóstico de AIDS, na vida das pessoas, torna-se mais um aspecto a ser vivenciado. Essas referem ter uma vida normal, buscam estudar, trabalhar e se relacionar com outras pessoas, e, no seu dia, mantêm-se ocupadas com as questões relacionadas à síndrome. ${ }^{15}$

Observa-se, portanto, que a descoberta da AIDS, na vida dos participantes, ocorreu de diferentes maneiras. Alguns já esperavam pelo resultado positivo do teste. Em meio a isso, emergiu o subtema vida normal apesar da doença, em que os pacientes relatam que vivem da mesma forma anterior ao diagnóstico, tornando a AIDS somente uma situação a mais integrada às suas vidas.

[...] eu já desconfiava de mim, já estava até esperando [...] (H3).

[...] eu me sinto feliz da vida, hoje eu sou aposentado, trabalho, não tenho tempo de pensar besteira, e estudo de noite ainda [...] a minha vida, é cada vez melhor [...] pra mim a vida minha énormal [...] (H1).

[...] eu me sinto bem, trabalho, como bem, não bebo, raramente tomo alguma taça de alguma coisa, tomo uma cervejinha sem álcool as vezes [...] minha vida é normal [...] (H2).

0 discurso acima apresenta como as pessoas conseguem adaptar-se às rotinas de acompanhamento do tratamento ao seu dia-a-dia, de maneira que não haja interferência na realização dos seus compromissos como seu trabalho e suas atividades de lazer referem que sua vida é normal. ${ }^{15}$

A partir dos discursos, emergiram também maneiras de enfrentamentos para se obter essa vida normal e, na maioria, é a fé em Deus que atua como subsídio para a força de viver e seguir em frente.
[...] naquela época eu era católico, a primeira coisa que eu procurei foi a igreja evangélica, hoje eu sou evangélico, eu sirvo ao Senhor, ao meu Deus, eu sou diácono duma igreja [...] curado (H1)

[...] Deus sempre está comigo. Eu acredito muito nele, se não fosse ele eu não tava aqui. (M1)

Normalmente as pessoas que têm AIDS utilizam a espiritualidade como apoio para o enfrentamento de sofrimentos e para a reorganização de suas vidas após o diagnóstico de AIDS. Isso que remete à relevância da religião, exemplificada em estudos realizados em que a maioria dos respondentes se referiram à importância da religião em suas vidas. ${ }^{16}$

Não é pouco frequente a crença na cura da AIDS por promessas encontradas em muitas igrejas. As promessas são fontes de alívio para o sofrimento advindo da doença. Assim, apesar das adversidades, os pacientes encontram na presença e no poder divino a ajuda e a força para se manterem firmes diante da realidade vivida. ${ }^{17-18}$

Dentre as adversidades, no desenvolvimento da dinâmica, emergiram situações de preconceito e discriminação. Essas situações envolvem a revelação do diagnóstico para a família. Nesse sentido, a pessoa que possui AIDS opta por não revelar sua sorologia, por falta de oportunidade ou de convívio com os familiares.

[...] Na minha família ninguém sabe que eu sou portador [...] não tenho mais pai, não tenho mais mãe, meus irmãos moram todos fora, só tenho uma filha que não mora aqui também, né? [...] ela não tem preconceito, conviveu no meio, mas enfim, a única pessoa que eu poderia contar seria ela, mas a gente se vê pouco, mais é por telefone [...] (H2).

A discriminação inicia, muitas vezes, na própria família, seja pelo julgamento, pela incompreensão ou pela não aceitação de que um membro da família tem o diagnóstico de AIDS $^{5}$. Assim, o silenciamento da doença na própria família pode significar uma forma de proteção, no intuito de não sofrer com as recriminações dentro do seu âmbito familiar.

[...] a minha familia sabe [...] mas eu fui recriminado (pela família) [...] mas no meu caso, a minha família sabe, milhares de pessoa sabem [...] (H1).

0 medo do preconceito está presente de maneira intensa na vida das pessoas que vivem com a infecção. Esse sentimento advindo dos familiares é percebido nas falas em que, por vezes, ter HIV ou AIDS é motivo de gozação e de medo. ${ }^{5}$

Pessoas que têm AIDS vivenciam necessidades de saúde, somadas ao preconceito e ao estigma em relação à velhice e, 
sobretudo, à velhice com AIDS. Esse preconceito, no cotidiano das pessoas, repercute em práticas de proteção e de não exposição da sua condição sorológica à sociedade. ., 18

[...] se alguém me perguntar se é, vou confirmar, e se não perguntarem, para mim está bom [...] sinto preconceito, que até acho[...]que claro pessoas que não sabem que eu sou portador, mas: ó fulano ali é portador [...]lsso aí dói na gente! 0 preconceito existe, e não pouco, porque eu conheço, a gente se conhece aqui. Às vezes vê um passar na rua, ah, aquele lá é portador, aidético, termo bem[...] vulgar(H2)

Em meio à convivência com a doença, pode-se notar certa dificuldade de falar sobre ela, que se revela no ocultamento da palavra em si. Assim, emergiu o subtema silêncio da condição sorológica.

0 silêncio pode aparecer de várias formas, tanto no momento em que se expressa outra palavra para se referir à AIDS como quando a palavra é oculta. Quando expressa, pode trazer um significado velado, necessitando ser interpretada. 0 silêncio, portanto, não só se configura pelo não dito e não expresso, mas também por meio de um diálogo. ${ }^{18}$

Em estudo realizado com familiares de crianças que têm AIDS, o silenciamento se deu por meio de metáforas utilizadas pelos depoentes do estudo. Estes, ao se referirem à AIDS, utilizam outra denominação como problema ou doença, 0 que preserva o silêncio da palavra, utilizado muitas vezes como uma estratégia de minimizar sentimentos de vergonha e medo que as pessoas sentem ao se referir a doença. ${ }^{18}$

Foi em 2003 [...] que eu apareci com esse problema também, que constatei essa doença [H1]

De repente eu comecei a ficar doente no serviço e descobrique tinha alguma coisa errada em mim [...] no resultado do exame deu que eu tinha esse problema (M1)

0 universo do silêncio aproxima-se da dimensão subjetiva como gestos, sentimentos, atitudes, os quais são considerados abstratos e indefinidos. Quando se trata de compreender o significado atribuído ao silêncio, deve-se considerar o conhecimento e sensibilidade com que as pessoas têm em determinado diálogo. 0 silêncio, dentro do discurso, é determinante da significação e ressignificação do dito ou não dito, pois se entrelaça nas palavras e não se abstrai delas. ${ }^{18}$

Nesse contexto, observa-se que a palavra AIDS possui uma associação significante a questões negativas como a morte, preconceito e discriminação às pessoas que têm a infecção.

\section{CONCLUSÕES}

Considerando a magnitude e a complexidade que envolvem as pessoas acima de 50 anos que possuem AIDS, percebeu-se um duplo desafio: o processo de envelhecer somado às implicações da doença no seu dia-a-dia.

0 processo de envelhecer caracteriza-se por limitações físicas, perdas fisiológicas e fragilidades emocionais, o que muitas vezes leva a uma situação de isolamento social. Essas mudanças tornam as pessoas mais suscetíveis ao desenvolvimento de outras doenças além da AIDS.

0 contexto do HIV/AIDS apresenta questões relevantes relacionadas ao dia-a-dia a partir do diagnóstico da doença, o qual se mostrou significativo para todos os participantes da pesquisa. Esses sentiram a necessidade de expressar de que maneira conheceram o seu diagnóstico e como repercutiu a doença em sua vida.

Considerou-se que, mesmo com a doença, levam uma vida normal, a qual se apresenta por meio de algumas formas de enfrentamento, salientando-se a fé em Deus como apoio para dar continuidade ao seu viver com a doença. E, ainda, identificam o preconceito e a discriminação que sofrem por sua condição sorológica.

Como forma de se proteger dessa situação, há o silenciamento da condição sorológica, a fim de que suas relações com as outras pessoas não sejam afetadas. Porém, 0 anonimato sorológico, ao mesmo tempo em que protege da discriminação, muitas vezes priva do acesso aos direitos sociais e de saúde.

Nesse sentido, a Enfermagem pode contribuir como parte da equipe de saúde, nas ações de cuidado e de educação em saúde, seja nas consultas individuais ou em grupos. Vislumbra-se a possibilidade de uma assistência integral, de modo que essas pessoas recebam apoio para o cuidado à saúde, que contemple as dimensões biológicas, clínica, social, ética e subjetiva, para viver melhor e com qualidade.

Assim, consideram-se necessárias ações com um cuidado compartilhado, entre a equipe de saúde, familiares/ cuidadores e pessoas acima de 50 anos que têm AIDS. Essas ações precisam ser pautadas na corresponsabilização dos envolvidos, tendo em vista à autonomia dessa população para o cuidado com a sua saúde e para as escolhas de sua vida.

\section{REFERÊNCIAS}

1. Ministério da Saúde (BR). Programa Nacional DST/AIDS. Bol Epidemiol AIDST. Versão preliminar. [On-line] 2009 Brasília(DF);2009.

2. Pottes FA, Brito AM, Gouveia GC, Araujo EC, Carneiro RM. Aids envelhecimento: características dos casos com idade igual ou maior que 50 anos em Pernambuco, de 1990 a 2000. Rev Bras Epidemiol 2007 set/dez; 10(3): 338-51. 
3. Ministério da Saúde (BR). Programa Nacional DST/AIDS. Bol Epidemiol AIDST. [on-line] 2008 jan/jun; [citado 2009 dez 14]; 5(1): [aprox. 64 telas]. Disponível em: http://portal.saude.gov.br/saude.

4. Lazzarotto A, Kramer AS, Hädrich M, Tonin M, Caputo P, Sprinz E. 0 conhecimento de HIV/AIDS na terceira idade: estudo epidemiológico no Vale do Sinos/Rio Grande do Sul. Brasil. Cienc Saude Colet. 2008; 13 (6): 1535-40.

5. Cechim PL, Selli L. Mulheres com HIV/AIDS: fragmentos de sua face oculta. Rev Bras Enferm. 2007; mar/abr; 60(2): 145-49.

6. Araújo MAL, Silveira CB. Vivências de mulheres com diagnóstico de doença sexualmente transmissível - DST. Esc Anna Nery 2007 dez; 11 (3): $479-86$.

7 Botti ML, Leite GB, Prado MF, Waidman MAP, Marcon SS. convivência e percepção d.o cuidado familiar ao portador de HIV/AIDS. Rev Enferm UERJ 2009 jul/set; 17(3): 400-45.

8. Cabral IE. 0 método criativo e sensível: alternativa de pesquisa na enfermagem. In: Gauthier JHM, organizador. Pesquisa em enfermagem: novas metodologias aplicadas. Rio de Janeiro(RJ): Guanabara Koogan; 1998. p.177-203.

9. Monteiro V. A imagem do álcool na vida dos adolescentes e sua relação com a prática educativa-dialógica da enfermeira. 1999. [dissertação]. Rio de Janeiro(RJ): Escola de Enfermagem Anna Nery, Universidade Federal do Rio de Janeiro; 1999.

10. Minayo MCS. 0 desafio do conhecimento: pesquisa qualitativa em saúde. $11^{\text {a }}$ ed. São Paulo(SP): Hucitec; 2008.

11. Padoin SMM, Souza IEO. A compreensão do temor como modo de disposição da mulher com HIV/AIDS diante da (im)possibilidade de amamentar. Texto\&Contexto Enferm. 2008 jul/set; 17(3): 510-18.

12. Ribeiro LCC, Jesus MVN. Avaliando a incidência dos casos notificados de aids em idosos no Estado de minas gerais no período de 1999 a 2004. Rev Cogitare Enferm. 2006 maio/ago; 11(2):113-16.

13. Bertoncini BZ, Moraes KS, Kulkamp IC. Comportamento sexual em adultos maiores de 50 anos infectados pelo HIV. DST: J Bras Doenças Sex Transm. 2007 mar/jun; 19(2): 75-79.

14. Brasileiro M, Freitas MIF. Representações sociais sobre aids de pessoas acima de 50 anos de idade, infectadas pelo HIV. Rev Latino-am Enfermagem. 2006 set/out; 14(5): 789-95.

15. Padoin SMM, Souza IE. A ocupação da mulher com HIV/AIDS: 0 cotidiano diante da (im) possibilidade de amamentar. DST: J Bras Doenças Sex Transm. 2006 out/dez; 18(4): 241-46.

16. Negreiros TCGM. Espiritualidade: desejo de eternidade ou sinal de maturidade? Rev Mal-Estar Subjetividade. 2003 set; 3(2): 275-91.

17. Maliska ICA, Padilha MICS. AIDS: a experiência da doença e a construção do itinerário terapêutico. Rev Eletr Enferm. 2007 set/ dez; 9(3): 687-99.
18. Gomes AMTG. Silêncio, silenciamento e ocultamento na terapia antiretroviral: desvelando o discurso de cuidadores de crianças. [doutorado]. Rio de Janeiro (RJ): Escola Anna Nery de Enfermagem, Universidade Federal do Rio de Janeiro.
Recebido em 05/05/2010 Reapresentado em 04/08/2010 Aprovado em 05/09/2010 